\title{
Synthesis of $\beta-\mathrm{AgVO}_{3}$ nanowires by hydrothermal and precipitation routes: a comparative study
}

\author{
Beatriz Rossi Canuto de Menezes ${ }^{1}\left[10\right.$. Renata Guimarães Ribas ${ }^{1} \cdot$ Vanessa Modelski Schatkoski $^{1}$. \\ Thaís Larissa do Amaral Montanheiro ${ }^{1}$. Cristiane Yumi Koga-Ito ${ }^{2}$. Gilmar Patrocínio Thim ${ }^{1}$
}

(c) Springer Nature Switzerland AG 2019

\begin{abstract}
Silver vanadate, especially $\beta-\mathrm{AgVO}_{3}$, have a wide range of technological applications due to remarkable biological, optical, and electrical features. The structure, morphology, and properties of $\beta-\mathrm{AgVO}_{3}$ are directly affected by synthesis conditions. A comparative study between two different synthesis routes (precipitation and hydrothermal) of $\beta-\mathrm{AgVO}_{3}$ was systematically investigated in this work. X-ray diffraction, Raman spectroscopy, scanning electron microscopy, zeta potential, and UV-visible spectrometry results showed that the hydrothermal method produced more homogeneous samples of $\beta-\mathrm{AgVO}_{3}$, with elevated purity and crystallinity. In addition, the sample of $\beta-\mathrm{AgVO}_{3}$ obtained by hydrothermal method had a wire-like morphology while that obtained by precipitation had irregular shape. Finally, the hydrothermal procedure showed more elevated reproducibility.
\end{abstract}

Keywords Silver vanadate $\cdot \beta-\mathrm{AgVO}_{3} \cdot$ Precipitation synthesis $\cdot$ Hydrothermal method

\section{Introduction}

Transition metal oxides, especially vanadates, are functional materials with increasing attention in nanotechnological fields. Their interesting optical, electrical, biological, and thermal properties are expanding their use in many industrial areas, such as photocatalyst [1], batteries [2], sensors [3], solar cells [4], anti-bacterial additive in paints $[5,6]$, and biomedical devices [7]. Among the vanadate compounds, silver vanadates are considered one of the most interesting, due to their remarkable properties, including higher crystallinity, narrow band gap, and significant anti-bacterial activity [8].

Silver and vanadium atoms show several oxidation states, which allow the formation of different silver vanadium oxides, which may contain $\mathrm{Ag}, \mathrm{V}$ and $\mathrm{O}$ in stoichiometric and non-stoichiometric ratios. Some common forms are $\mathrm{Ag}_{2} \mathrm{~V}_{4} \mathrm{O}_{11}, \mathrm{Ag}_{3} \mathrm{VO}_{4}, \mathrm{Ag}_{4} \mathrm{~V}_{2} \mathrm{O}_{7}$ and $\mathrm{AgVO}_{3}$ [9]. Their properties are directly dependent on their composition, size, crystalline structure and surface characteristics. The most common form of silver vanadate is $\mathrm{AgVO}_{3}$, a stable one-dimensional material with several applications, such as: sensors, batteries, photocatalytic for dye photodegradation, antimicrobial agents, and additive for dental prostheses [10-12].

$\mathrm{AgVO}_{3}$ can be crystallized in four different structures. $\mathrm{a}-\mathrm{AgVO}_{3}, \mathrm{Y}-\mathrm{AgVO}_{3}$ and $\delta-\mathrm{AgVO}_{3}$ are metastable and $\beta-\mathrm{AgVO}_{3}$ is the only one thermodynamically stable. $\mathrm{a}-\mathrm{AgVO}_{3}$ and $\beta-\mathrm{AgVO}_{3}$ show one-dimensional morphologies, and they can be found in the form of nanowires, nanorods or nanotubes. The a-AgVO ${ }_{3}$ phase can become irreversibly $\beta-\mathrm{AgVO}_{3}$ at temperatures close to $200^{\circ} \mathrm{C}$ [13]. It has monoclinic crystalline system, space group $C_{m}$

$\triangle$ Beatriz Rossi Canuto de Menezes, beatriz1menezes@gmail.com | 'Laboratório de Plasmas e Processos (LPP), Instituto Tecnológico de Aeronáutica (ITA), Praça Marechal Eduardo Gomes, 50, Vila das Acácias, São José dos Campos, SP 12228970, Brazil. ${ }^{2}$ Laboratório de Genoma, Instituto de Ciência e Tecnologia do Campus de São José dos Campos (ICT), Universidade Estadual Paulista (UNESP), Estrada Dr. Altino Bondensan, 500, Eugênio de Melo, São José dos Campos, SP 12247-016, Brazil. 
and crystallographic parameters $a=17,87, b=3,58$ and $c=8,036 \AA$ (JCPDS 29-1154) [10].

Silver vanadates present the most complex structures among the vanadate compounds due to their various number of phases [14]. Different reaction conditions, such as precursor materials, reagent stoichiometry, synthesis method, reaction temperature, among others, can generate silver vanadates with different structures and properties [15, 16]. Zhang et al. [17] prepared $\mathrm{Ag}_{2} \mathrm{~V}_{4} \mathrm{O}_{11}$ nanowires, $\mathrm{a}-\mathrm{AgVO}_{3}$ microrods, and $\beta-\mathrm{AgVO}_{3}$ nanowires using the hydrothermal method with different parameters. The authors showed that different phases can be obtained by controlling the hydrothermal reaction parameters, as $\mathrm{pH}$, time, and precursors. De Oliveira et al. [18] observed similar behavior. They produced $\beta-\mathrm{AgVO}_{3}$ crystals by precipitation method at 30,60 , and $90^{\circ} \mathrm{C}$ to determine the effect of temperature on the materials properties. According to the results, the sample obtained at $90^{\circ} \mathrm{C}$ presented higher crystallinity degree than the samples obtained at 30 and $60^{\circ} \mathrm{C}$. Consequently, the band gap energy was lower for the sample produced at $90{ }^{\circ} \mathrm{C}(1.88 \mathrm{eV})$, when compared with the samples produced at $30^{\circ} \mathrm{C}(2.04 \mathrm{eV})$ and $60^{\circ} \mathrm{C}(2.03 \mathrm{eV})$.

A complete understanding of the synthesis process can allow the production of materials with improved structure, morphology, and properties. In this way, this work specifically intends to explain detailly the effects of two synthesis routes, hydrothermal and precipitation, on size, morphology, structure, and properties of $\beta-\mathrm{AgVO}_{3}$ powders. The influence of $\mathrm{Ag} / \mathrm{V}$ molar ratio on $\beta-\mathrm{AgVO}_{3}$ crystallographic phases was also analyzed, since it has a great effect on the electrochemical and antimicrobial properties [17].

\section{Materials and methods}

\subsection{Synthesis of $\beta-\mathrm{AgVO}_{3}$ by precipitation route}

$\beta-\mathrm{AgVO}_{3}$ nanowires were synthesized by a precipitation reaction of silver nitrate $\left(\mathrm{AgNO}_{3}, \mathrm{Neon}, 99.8 \%\right)$ and ammonium metavanate $\left(\mathrm{NH}_{4} \mathrm{VO}_{3}, \mathrm{Neon}, 99 \%\right)$ using two different molar ratios of $\mathrm{Ag} / \mathrm{V}: 1 / 1$ and $2 / 1.1 \mathrm{mmol}$ of $\mathrm{AgNO}_{3}$ and $1 \mathrm{mmol}$ of $\mathrm{NH}_{4} \mathrm{VO}_{3}$ were separately dissolved in $35 \mathrm{~mL}$ of distilled water at $60^{\circ} \mathrm{C}$, under magnetic stirring for $20 \mathrm{~min}$. $\mathrm{NH}_{4} \mathrm{VO}_{3}$ solution was mixed with $\mathrm{AgNO}_{3}$ solution, forming $\beta-\mathrm{AgVO}_{3}$ precipitate. The precipitate was filtered and washed with distilled water several times. Then, the material was dried in conventional furnace at $60^{\circ} \mathrm{C}$ for $12 \mathrm{~h}$. The samples were labeled as P1 (Ag/V: 1/1) and P2 (Ag/V: 2/1).

\subsection{Synthesis of $\beta-\mathrm{AgVO}_{3}$ by hydrothermal route}

The mixtures obtained in step 2.1 ( $\mathrm{P} 1$ and $\mathrm{P} 2$ with respective supernatant, before filtered step) were placed in a Teflon-lined stainless-steel autoclave, heated to $180^{\circ} \mathrm{C}$ for $16 \mathrm{~h}$. The time and temperature of reaction were defined based in the $a \rightarrow \beta \mathrm{AgVO}_{3}$ phase transformation. Under hydrothermal conditions (relatively high pressures), the metastable $\mathrm{a}-\mathrm{AgVO}_{3}$ phase can be irreversible transformed into $\beta-\mathrm{AgVO}_{3}$ at temperatures above $180^{\circ} \mathrm{C}$ and reaction time higher than $15 \mathrm{~h}[16,17]$. The system was cooled to room temperature. Then, the collected product was filtered and washed with distilled water. Finally, the material was dried in conventional furnace at $60^{\circ} \mathrm{C}$ for $12 \mathrm{~h}$. For this synthesis, the sample produced with molar ratio of $\mathrm{Ag} / \mathrm{V}$ : 1/1 was labeled as $\mathrm{H} 1$, while the $\mathrm{Ag} / \mathrm{V}: 2: 1$ was labeled $\mathrm{H}$ 2.

\section{Characterizations}

X-ray diffraction (XRD) analysis was performed using a PANalytical Philips X'Pert diffractometer operating with CuKa radiation $(\lambda=1.54178 \AA$ ) at $45 \mathrm{kV}$ and $40 \mathrm{~mA}$. The data were collected in the range $10^{\circ}<2 \theta<70^{\circ}$ with $\Delta \theta=0.02^{\circ}$ and 30 s per step. Raman spectroscopy was performed in a Horiba LabRam HR Evolution equipment with $532 \mathrm{~nm}$ laser excitation. Field emission scanning electron microscopy (FE-SEM) were carried out in a Jeol JSM-5310 at accelerating voltage of $30 \mathrm{kV}$. Zeta potential values were obtained in dynamic light scattering equipment, Beckman Coulter Delsa Nano. Samples were previously dispersed in deionized water $(\mathrm{pH}=5.0)$ and the measurements were performed at $25^{\circ} \mathrm{C}$ at an angle of $15^{\circ}$. The equation of Smoluchowski [19] was used to obtain zeta potential. UV-Vis absorption spectrum was obtained in a Thermo Scientific Evolution 220 UV-Visible spectrophotometer by measure of absorbance from $800 \mathrm{~nm}$ to $260 \mathrm{~nm}$ using silica cuvette.

\section{Results and discussion}

Figure 1 shows the X-ray diffraction (XRD) pattern of the resulting silver vanadate nanostructures prepared by precipitation and hydrothermal method. Samples P1 and $\mathrm{P} 2$ exhibited diffractions peaks indexed to monoclinic $\beta-\mathrm{AgVO}_{3}$ (JCPDS 29-1154), cubic silver oxide phases with chemical formula of $\mathrm{Ag}_{2} \mathrm{O}_{3}$ (JCPDS 01-072-0607) and AgO (JCPDS 01-076-1489) and metallic silver (JCPDS 81-1740). Samples $H 1$ and $H 2$ showed diffractions peaks attributed to monoclinic $\beta-\mathrm{AgVO}_{3}$ (JCPDS 29-1154) and 
Fig. 1 XRD patterns samples $\mathrm{P} 1, \mathrm{P} 2, \mathrm{H} 1$ and $\mathrm{H} 2$

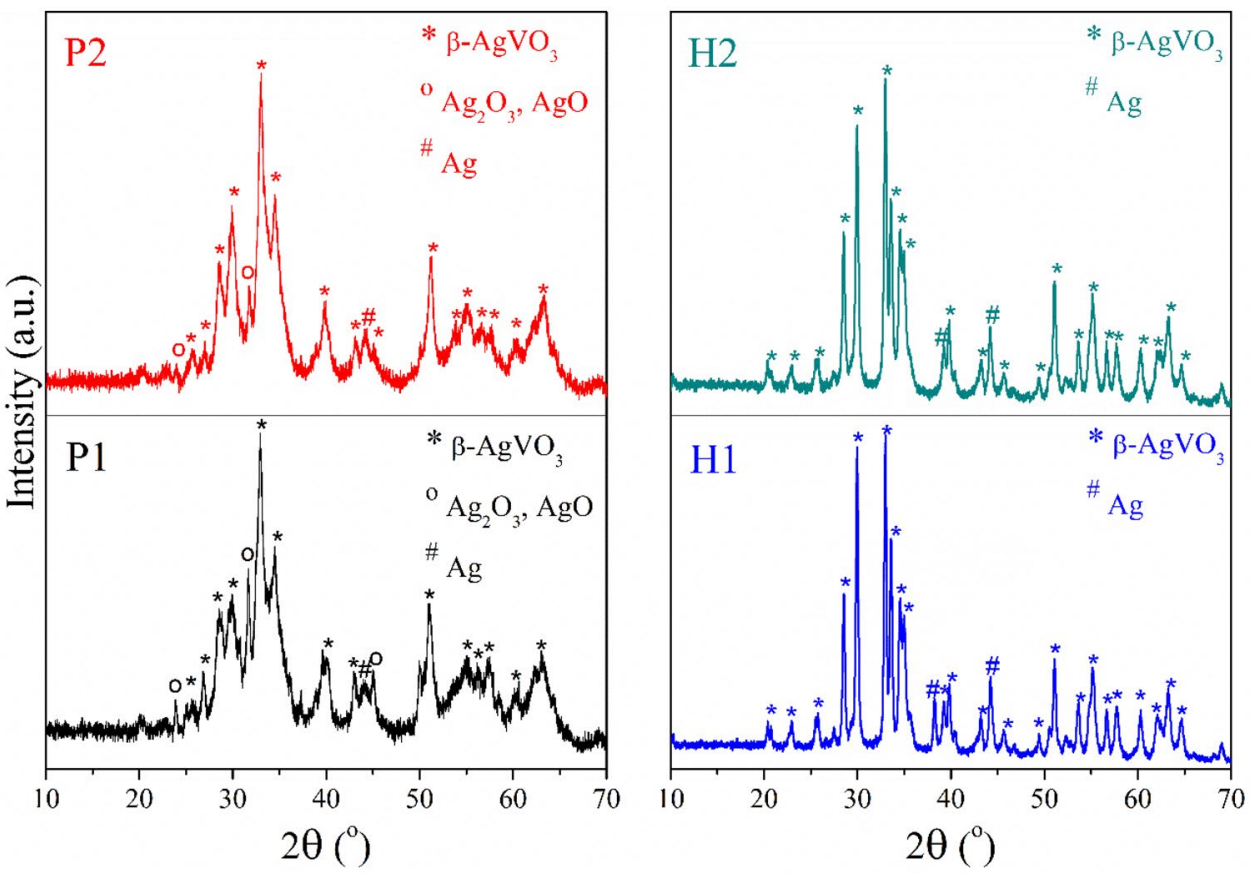

metallic silver (JCPDS 81-1740) [6, 20]. Therefore, the two peaks attributed to $\mathrm{Ag}$ was verified in all samples. $\mathrm{Ag}$ is an interesting metal for biological and for batteries applications, since it may improve the antimicrobial activity and enhance the electrochemical performance due to the improved conductivity [12]. Figure 1 also shows that samples $\mathrm{H} 1$ and $\mathrm{H} 2$ are constituted only of $\beta-\mathrm{AgVO}_{3}$ besides metallic silver, while samples $\mathrm{P} 1$ and $P 2$ showed diffractions peaks indexed to silver oxides $\left(\mathrm{Ag}_{2} \mathrm{O}_{3}\right.$ and $\left.\mathrm{AgO}\right)$ along with $\mathrm{\beta}-\mathrm{AgVO}_{3}$.

The crystallinity degree of each samples was estimated using the background of the XRD patterns using the Krimm and Tobolsky [21, 22]. The crystallinity degree of multiphase samples (CD) was calculated from the ratio between the sum of all crystalline diffracted areas $\left(A_{C}\right)$ and the total area of diffraction $\left(A_{T}=\right.$ crystalline + amorphous), as shown in Eq. 1:

$C D=\left(\frac{A_{C}}{A_{T}}\right) \times 100$

Sample $\mathrm{P} 1$ and $\mathrm{P} 2$ showed average crystalline degrees of $68 \%$ and $63 \%$, while, $\mathrm{H} 1$ and $\mathrm{H} 2$ were $81 \%$ and $79 \%$, respectively. Therefore, the hydrothermal synthesized samples showed increased crystalline phase when compared to precipitated samples. The higher values of crystalline degree of samples $\mathrm{H} 1$ and $\mathrm{H} 2$ is due to high temperature and pressure of the hydrothermal process, which were $180^{\circ} \mathrm{C}$ and about $1.7 \mathrm{MPa}$. In the hydrothermal process, the precursors dissolve in the solvent and recrystallize in nanostructured form. Initially, tiny crystalline nuclei of $\mathrm{a}-\mathrm{AgVO}_{3}$ emerge in the supersaturated solution system, which grow in the form of microrods, following the "Ostwald-ripening process". In the first $4 \mathrm{~h}$ of reaction, longer $\mathrm{a}-\mathrm{AgVO}_{3}$ microrods are formed. Then, with longer reaction time, the $\mathrm{a}-\mathrm{AgVO}_{3}$ microrods split into $\beta-\mathrm{AgVO}_{3}$ nanowires. The phase/ morphology transformation of a-AgVO ${ }_{3}$ microrods into $\beta-\mathrm{AgVO}_{3}$ nanowires, under hydrothermal conditions, occurs at around $180{ }^{\circ} \mathrm{C}$ and relatively high pressure (1.7 MPa) [17]. The hydrothermal conditions guarantee the formation of nanomaterials with excellent organization and crystallinity, reducing the amorphous structure and controlling the grain size [23].

Figure 2 displays the Raman spectra of samples P1, P2, $\mathrm{H} 1$ and $\mathrm{H} 2$. All samples presented peaks related to formation of $\beta-\mathrm{AgVO}_{3}$. The most intense peak at $884 \mathrm{~cm}^{-1}$ can be attributed to stretching vibrations of $\mathrm{V}-\mathrm{O}-\mathrm{Ag}, \mathrm{Ag}-\mathrm{O}-\mathrm{Ag}$ and $\mathrm{O}-\mathrm{V}-\mathrm{O}$ [24-28]. That band at $840 \mathrm{~cm}^{-1}$ is related to the stretching vibrations of $\mathrm{V}-\mathrm{O}$ groups in $\left(\mathrm{V}_{2} \mathrm{O}_{7}\right)^{-4}$ ion or to Ag-O-V stretching vibrations $[24,27,28]$. The band at $805 \mathrm{~cm}^{-1}$ is associated with stretching vibrations of Ag-O-Ag bridges $[25,27,28]$, while that band at $728 \mathrm{~cm}^{-1}$ is related to $\mathrm{VO}_{4}$ deformation modes [24-27]. The stretching vibrations of $\mathrm{Ag}-\mathrm{O}-\mathrm{V}$ and asymmetric stretching of $\mathrm{V}-\mathrm{O}-\mathrm{V}$ in the polymeric chains of metavanadate are assigned to bands at 701 and $515 \mathrm{~cm}^{-1}$ [24-28]. Raman bands at 384 and $334 \mathrm{~cm}^{-1}$ are attributed to the asymmetric deformation of $\mathrm{VO}_{4}{ }^{3-}$ tetrahedron $[29,30]$. The bands around 271 and $243 \mathrm{~cm}^{-1}$ are related to the asymmetrical and symmetrical folding of $\mathrm{VO}_{4}{ }^{3-}$ tetrahedron, respectively. Those bands below $200 \mathrm{~cm}^{-1}$ are related to 
Fig. 2 Raman spectra of samples $\mathrm{P} 1, \mathrm{P} 2, \mathrm{H} 1$ and $\mathrm{H} 2$

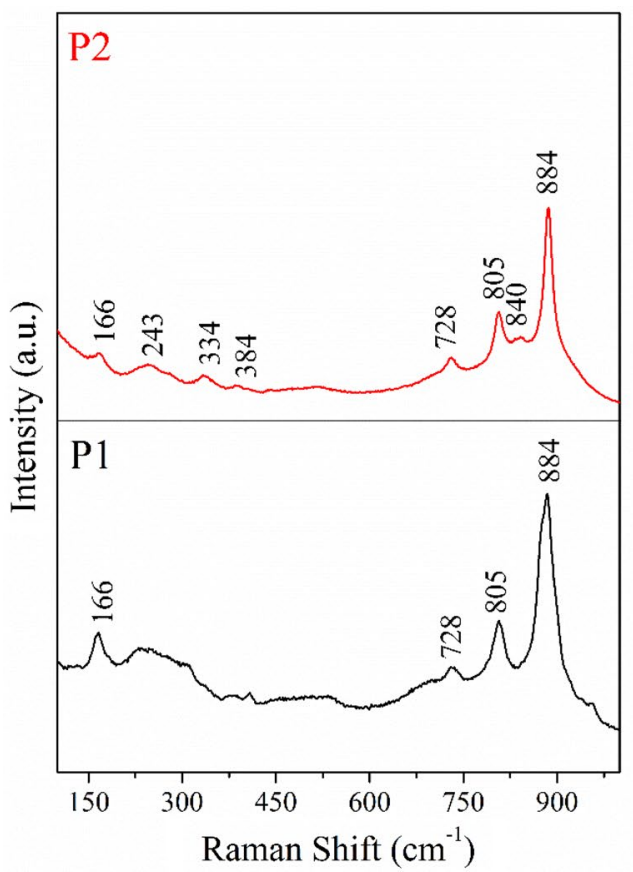

the collective vibration modes of the phonon vibrations of the crystal lattice [31, 32].

Figure 2 shows that the Raman bands of samples $\mathrm{H} 1$ and $\mathrm{H} 2$ are related to $\beta-\mathrm{AgVO}_{3}$. Raman bands of samples $\mathrm{P} 1$ and $\mathrm{P} 2$ shows the disappearance of some peaks related to $\beta-\mathrm{AgVO}_{3}$ at frequencies (under $500 \mathrm{~cm}^{-1}$ ). The XRD patterns, in general, reveal the long-range ordering of the materials in the length of periodicity of 40 to $100 \AA$, showing structural information of several unit cells $[28,33,34]$. In this way, a periodicity over a length of at least $50 \AA$ is necessary to obtain an XRD pattern from a specific material. This requirement makes $X R D$ technique insensitive to structural changes that occur under such range order [34]. On the other hand, Raman spectroscopy is very sensitive to the structure symmetry, being suitable for molecularlevel investigations [35]. The presence of any disorder in the system, especially those caused by oxygen displacement, will result in drastic changes in the Raman spectrum of a perfect crystal lattice [36, 37].

In general, the intensity of Raman bands become less intense and wider when samples have structural disorders, which results in a breakdown of translational symmetry [36]. Broad modes could also be related to disorder from metal-oxygen vacancies [38]. Raman bands of a perfect crystal shows narrow lines $[28,33]$. Samples P1 and P2 showed weak and overlapped bands suggesting a great amount of structural disorders, as metal-oxygen vacancies. However, samples $\mathrm{H} 1$ and $\mathrm{H} 2$ showed narrow bands with high intensity, indicating more ordered structures. The results of XRD and Raman spectroscopy suggested that samples $\mathrm{H} 1$ and $\mathrm{H} 2$ have more ordered structures with higher crystallinity, when compared to samples P1 an P2. One-dimensional structures with high crystallinity are suitable for several applications. In the electrical field, wirelike crystalline $\beta-\mathrm{AgVO}_{3}$ can be used as cathode for lithium batteries due to the higher transport of electrons $[12,17]$.

Figure 3 shows the SEM micrographs of samples P1, P2, $\mathrm{H} 1$ and $\mathrm{H} 2$. A significant difference in the crystal shapes can be observed. Samples P1 and P2 are constituted of
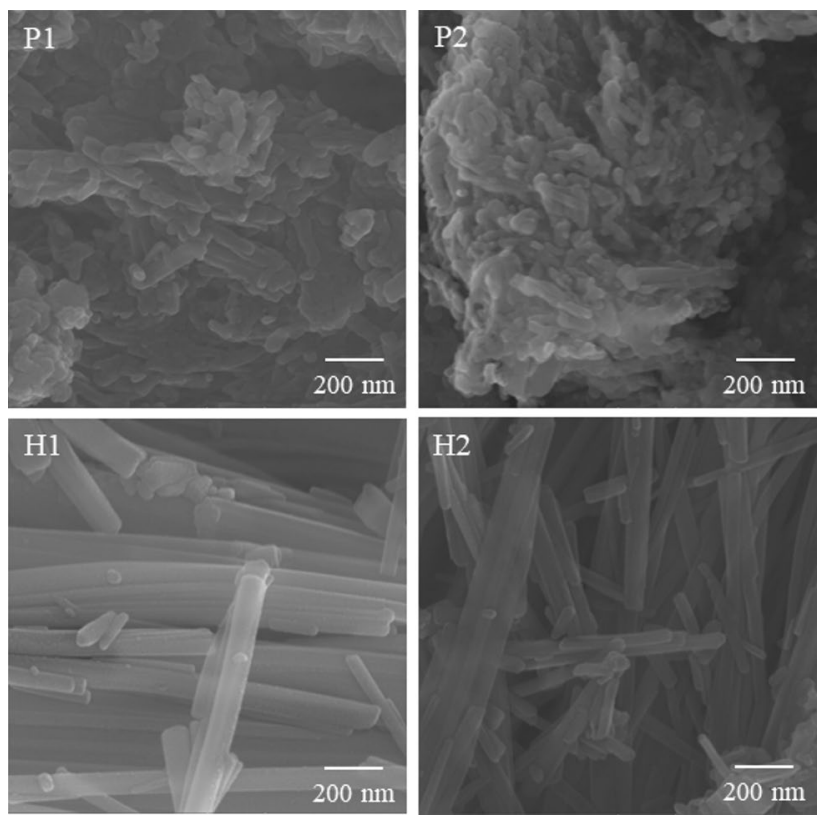

Fig. 3 SEM micrographs of samples $\mathrm{P} 1, \mathrm{P} 2, \mathrm{H} 1$ and $\mathrm{H} 2$

\section{SN Applied Sciences}


particles of irregular shape with some rodlike structures. However, these structures are irregular and heterogeneous, with different diameters and lengths. In the precipitation route, the nucleation plays a major role when compared to the crystal growth. In this case, most of the solute crystallize in the nucleation stage, as a mass precipitation process. The particles are formed by the ordered aggregation of several nucleus rather than by crystal growth [39]. As a result, irregular and heterogeneous particles are produced, since there is not enough time to grow and rearrange in preferential directions to generate a one-dimensional material. Sample P2 was more agglomerated, but it has more rodlike structures when compared to sample $\mathrm{P} 1$. This result indicates that higher $\mathrm{Ag} / \mathrm{V}$ ratio was more favorable for one-dimensional silver vanadate production in precipitation reaction.

Figure $3 c$, d reveal that the hydrothermal method produced samples with one-dimensional morphology with length of several tens of micrometers. Both samples $\mathrm{H} 1$ and $\mathrm{H} 2$ showed uniform and homogeneous wirelike structures, without the presence of particles with other shapes. This is an indication that hydrothermal methodology can produce one-dimensional (wirelike) $\beta-\mathrm{AgVO}_{3}$ particles with good uniformity. As mentioned before, in the hydrothermal route, the precursors gradually dissolve and recrystallize in the form of microrods. Since the reaction take place in higher temperatures and longer times, there is enough time to the particle grow in the energy favorable direction. First, a- $\mathrm{AgVO}_{3}$ microrods are produced, which are splitted into $\beta-\mathrm{AgVO}_{3}$ nanowires $[17,40]$. Onedimensional nanostructures have great potential to be used in electronics, optoelectronics, and memory devices. $\beta-\mathrm{AgVO}_{3}$ wirelike morphology allows an efficient transport of electrons, expanding their use as cathode materials for lithium batteries $[11,16]$.
The diameters of the nanowires of samples $\mathrm{H} 1$ and $\mathrm{H} 2$ were determined from SEM micrograph and the distribution histograms are shown in Fig. 4. A number of 100 nanowires per sample were taken into account to allow a meaningful comparison. The histogram of sample $\mathrm{H} 1$ presented an asymmetry towards values under $100 \mathrm{~nm}$ and the diameter around 60 to $95 \mathrm{~nm}$. Sample H2 presented a narrow and symmetrical nanowire diameter distribution, with most of nanowires having diameters between 45 and $70 \mathrm{~nm}$. Sample H2 showed nanowires less aggregated, with smaller diameter when compared to $\mathrm{H} 1$. In addition, most nanowires of sample $\mathrm{H} 1$ is parallel to one another and tightly bundled together. So, synthesis of $\beta-\mathrm{AgVO}_{3}$ nanowires performed with higher $\mathrm{Ag} / \mathrm{V}$ ratio produced $\beta-\mathrm{AgVO}_{3}$ nanowires with narrow diameter distribution and less aggregates.

SEM micrographs confirmed the results observed in XRD and Raman spectroscopy. As expected, samples P1 and $\mathrm{P} 2$ presented more heterogeneous structures without regular shapes, which may be related to the formation of silver oxides that were identified by XRD. The onedimensional structures present in the sample are smaller in size than in samples $\mathrm{H} 1$ and $\mathrm{H} 2$, as suggested by the broader peaks and bands of XRD and Raman. The hydrothermal treatment under higher pressures $(1.7 \mathrm{MPa})$, temperatures $\left(180^{\circ} \mathrm{C}\right)$, and times $(15 \mathrm{~h})$ increases the particle size when compared to the precipitation reaction under lower temperatures $\left(60^{\circ} \mathrm{C}\right)$ and times $(20 \mathrm{~min})$. In addition, as indicated by Raman spectroscopy, the silver vanadate produced by the hydrothermal method presented more organized, crystalline and homogeneous $\beta-\mathrm{AgVO}_{3}$ nanowires.

The stability of a colloidal suspension may be determined by measuring the zeta potential of particles, which is related to the surface particle charges of a dispersion.
Fig. 4 SEM histogram of the nanowire diameter distribution of $\mathrm{H} 1$ and $\mathrm{H} 2$

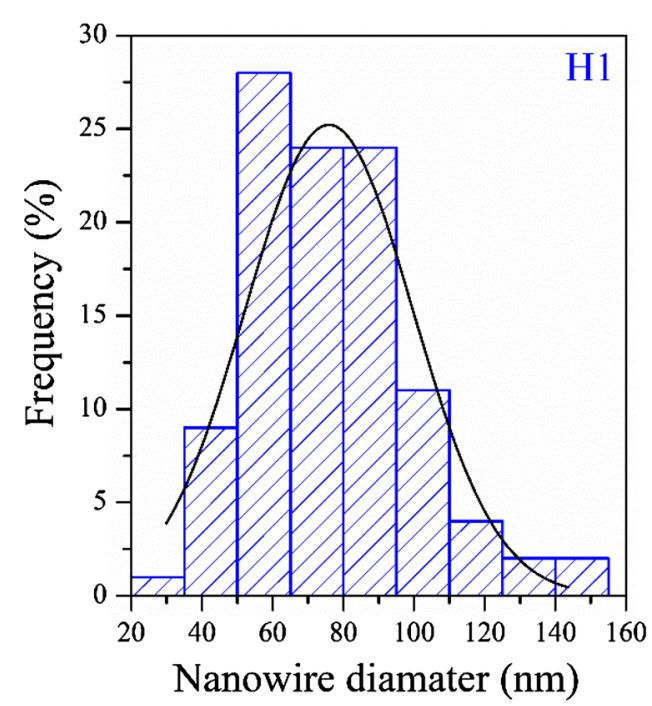


The particle charge of particles in dispersions is strongly influenced by the $\mathrm{pH}$ of the medium [41]. The zeta potentials of samples $\mathrm{P} 1, \mathrm{P} 2, \mathrm{H} 1$, and $\mathrm{H} 2$ are shown in Table 1. Particles with zeta potential greater than $\pm 25 \mathrm{mV}$ are considered to form stable colloidal suspensions $[42,43]$.

Table 1 shows that samples P1, P2, H1 and H2 had negative zeta potentials, regardless the synthesis route and molar ratio of precursors. The negative values of zeta potentials are attributed to negatively charged hydroxyl groups present on the surface of particles, which lead to negatively charged particles $[44,45]$. In the presence of water, the outermost surface oxygens of metal oxides particles hydrate, forming a high density of hydroxyl groups. These hydrated polar surface groups allow the formation of hydrogen bonds and other forces to the surfaces when in contact with polar liquids $[46,47]$. As a result, a colloidal suspension is formed, which is showed by the potential zeta values (higher than $25 \mathrm{mV}$, in modulus). $\mathrm{AgVO}_{3}$ nanowires synthesized by Artal et al. [48] presented zeta potential of $-0.1 \mathrm{mV}$, confirming the negative behavior of the electric charges of these samples.

Sample $\mathrm{H} 1$ is a more stable colloidal dispersion since the higher (in modulus) value of zeta potential prevents the agglomeration of particles due to the reduction of intraparticle attractive forces [49]. Therefore, the presence of hydroxyl functional groups on the surface of $\mathrm{AgVO}_{3}$ particles may aid the functionalization process with another chemical groups, expanding the applications of $\mathrm{AgVO}_{3}$ particles as reinforcement agent in nanocomposites. $\beta-\mathrm{AgVO}_{3}$ have great potential of applications as fillers in

Table 1 Zeta potential of samples $\mathrm{P} 1, \mathrm{P} 2, \mathrm{H} 1$ and $\mathrm{H} 2$

\begin{tabular}{llll}
\hline \multicolumn{4}{l}{ Zeta potential $(\mathrm{mV})$} \\
\hline P1 & P2 & H1 & H2 \\
\hline-30.31 & -23.91 & -35.56 & -29.41 \\
\hline
\end{tabular}

biomedical prosthesis, especially in dentistry, due to their antibacterial properties [22], which is enhanced by the presence of metallic silver on $\beta-\mathrm{AgVO}_{3}$ structure (showed by $X R D$ ). Also, electrode nanocomposites can also be produced, combining the high energy density and long-term stability of $\beta-\mathrm{AgVO}_{3}$ with the high electrical conductivity of carbon materials [11].

In order to investigate the alterations of optical properties induced by different synthesis route, the samples were subject to analysis of UV-vis absorption spectra. The UV-vis spectra of samples $\mathrm{P} 1, \mathrm{P} 2, \mathrm{H} 1$ and $\mathrm{H} 2$ are shown in Fig. 5.

Samples $\mathrm{P} 1, \mathrm{P} 2, \mathrm{H} 1$ and $\mathrm{H} 2$ exhibited absorption in the UV and visible light region. The optical band gap energies $\left(E_{g}\right)$ of each sample were estimated from absorption coefficients as function of wavelength using Tauc relation: $(\alpha h v)^{n}=A\left(h v-E_{g}\right)$, where $\mathrm{A}$ is the relative constant for the material, $a$ is the absorption coefficient and $h v$ is the photon energy. The index $\mathrm{n}$ is a constant associated with electronic transitions ( $n=0.5$ for direct transitions, $n=2$ for indirect transitions) [50]. Figure $4 \mathrm{~b}$ shows the calculated $\mathrm{E}_{\mathrm{g}}$ for samples P1, P2, $\mathrm{H} 1$ and $\mathrm{H} 2$ as $2.50 \mathrm{eV}, 2.45 \mathrm{eV}, 1.72 \mathrm{eV}$ and $1.90 \mathrm{eV}$, respectively, which agree with the values obtained by Sivakumar et al. [50] and Zhang and Min [51].

The morphology and size of materials have important effects on optical properties. The band gap energy increase with the reduction of the particle size due to the quantum confinement in semiconductors nanoparticles. Moreover, the percentage of amorphous phase present in the semiconductors influences the values of $\mathrm{E}_{\mathrm{g}}$. In general, materials that are heat treated or synthesized at higher temperatures have more organized structures due to the reduction of structural defects and oxygen vacancies, resulting in reductions of band gap energy [28], justifying the band gap reduction for samples $\mathrm{H} 1$ and $\mathrm{H} 2$. Therefore, a reduction in $\mathrm{Eg}$ values of samples $\mathrm{H} 1$ and $\mathrm{H} 2$ were expected since the samples prepared by hydrothermal
Fig. 5 a UV/Vis analysis of samples $\mathrm{P} 1, \mathrm{P} 2, \mathrm{H} 1$ and $\mathrm{H} 2$; b Plots of $(\mathrm{ahv})^{2}$ versus photon energy (hv) of $\mathrm{AgVO}_{3}$ prepared by different routes
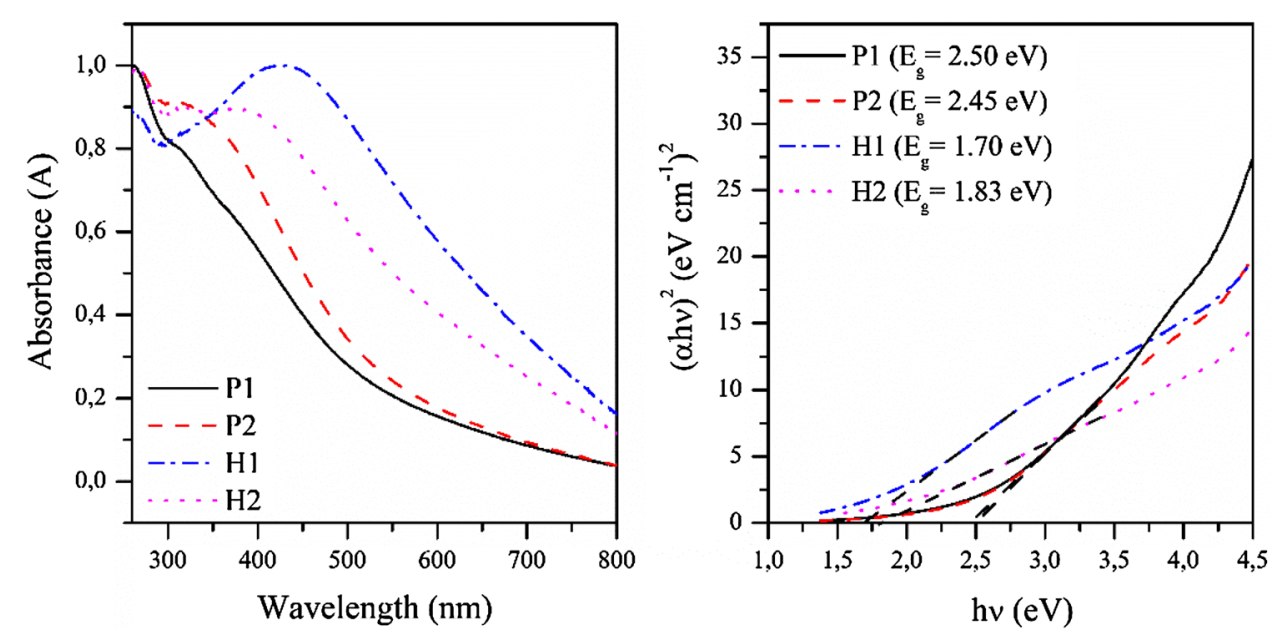
$(\mathrm{H} 1$ and $\mathrm{H} 2)$ route showed higher crystallinity than samples prepared by precipitation route (P1 and $\mathrm{P} 2$ ). Some works have been demonstrated that narrows band gaps are related to better photocatalytic activity [52]. Since $\beta-\mathrm{AgVO}_{3}$ is an efficient photocatalyst under visible light radiation [53], the samples produced by hydrothermal routes $(\mathrm{H} 1$ and $\mathrm{H} 2)$ is expected to present better photocatalytic activity than the samples synthesized by precipitation (P1 and P2).

\section{Conclusions}

A great understanding of the synthesis of silver vanadate and the comparison of two manufacturing processes, precipitation and hydrothermal method was reported. As shown by XRD analysis and Raman spectroscopy, both synthesis techniques produced the phase $\beta-\mathrm{AgVO}_{3}$. However, the precipitation route produced $\beta-\mathrm{AgVO}_{3}$ with lower purity, crystallinity, and a poor reproducible process. On the other hand, the use of hydrothermal method provided the adequate medium for the formation of $\beta-\mathrm{AgVO}_{3}$ with higher purity, high crystallinity, homogeneous and wirelike morphology and, mainly, a process with high reproducibility. Although smaller particles are desired in many nanotechnological applications, the use materials with better crystallinity, higher purity and a high reproducible process is usually more important. In this context, the results showed that hydrothermal methodology is more indicated to produce $\beta-\mathrm{AgVO}_{3}$ nanowires.

Funding This work was supported by the Fundação de Amparo à Pesquisa do Estado de São Paulo (Grant: 2017/02846-5, 2017/248734, 2018/12035-7); and the Coordenação de Aperfeiçoamento de Pessoal de Nível Superior.

\section{Compliance with ethical standards}

Conflict of interest The authors declare that they have no conflict of interest.

\section{References}

1. Zong L, Cui P, Qin F, Zhao K, Wang Z, Yu R (2017) Heterostructured bismuth vanadate multi-shell hollow spheres with high visible-light-driven photocatalytic activity. Mater Res Bull $86: 44-50$

2. Sottmann J, Herrmann M, Vajeeston P, Ruud A, Drathen C, Emerich $\mathrm{H}$, Wragg DS, Fjellvåg $\mathrm{H}$ (2017) Bismuth vanadate and molybdate: stable alloying anodes for sodium-ion batteries. Chem Mater 29:2803-2810

3. Karthik R, Kumar JV, Chen S-M, Kumar PS, Selvam V, Muthuraj $V$ (2017) A selective electrochemical sensor for caffeic acid and photocatalyst for metronidazole drug pollutant: a dual role by rod-like $\mathrm{SrV}_{2} \mathrm{O}_{6}$. Sci Rep 7:7254

4. El-Mellouhi F, Akande A, Motta C, Rashkeev SN, Berdiyorov G, Madjet ME-A, Marzouk A, Bentria ET, Sanvito S, Kais S, Alharbi FH (2017) Solar cell materials by design: hybrid pyroxene cornersharing $\mathrm{VO}_{4}$ tetrahedral chains. Chemsuschem 10:1931-1942

5. Bhoge YE, Patil VJ, Deshpande TD, Kulkarni RD (2017) Synthesis and anticorrosive performance evaluation of zinc vanadate pigment. Vacuum 145:290-294

6. Holtz RD, Souza Filho AG, Brocchi M, Martins D, Durán N, Alves OL (2010) Development of nanostructured silver vanadates decorated with silver nanoparticles as a novel antibacterial agent. Nanotechnology 21:185102

7. Nagaraju G, Ramasami AK, Balakrishna GR, Dupont J (2018) Ionic liquid-assisted hydrothermal synthesis of silver vanadate nanorods. Iran J Sci Technol A 42:451-456

8. Guo J, Liang J, Yuan X, Jiang L, Zeng G, Yu H, Zhang J (2018) Efficient visible-light driven photocatalyst, silver (meta)vanadate: synthesis, morphology and modification. Chem Eng J 352:782-802

9. Cheng F, Chen J (2011) Transition metal vanadium oxides and vanadate materials for lithium batteries. J Mater Chem 21:9841-9848

10. de Melo Monteiro AP, Dias Holtz R, Carneiro Fonseca L, Zanini Martins $\mathrm{CH}$, de Sousa M, de Luna LAV, de Sousa Maia DL, Alves $\mathrm{OL}$ (2018) Nano silver vanadate $\mathrm{AgVO}_{3}$ : synthesis, new functionalities and applications. Chem Rec 18:973-985

11. Liang L, Xu Y, Yong Lei, Liu H (2014) 1-Dimensional $\mathrm{AgVO}_{3}$ nanowires hybrid with 2-dimensional graphene nanosheets to create 3-dimensional composite aerogels and their improved electrochemical properties. Nanoscale 6:3536-3539

12. Liang S, Zhou J, Zhang X, Tang Y, Fang G, Chen T, Tan X (2013) Hydrothermal synthesis of $\mathrm{Ag} / \beta-\mathrm{AgVO}_{3}$ nanobelts with enhanced performance as a cathode material for lithium batteries. Cryst Eng Commun 15:9869-9873

13. Oliveira RC, Teixeira MM, Costa JPC, Penha M, Francisco EM, da Silva JS, Li MS, Longo E, Gracia L, Andrés J (2018) a- and $\beta-\mathrm{AgVO}_{3}$ polymorphs as photoluminescent materials: an example of temperature-driven synthesis. Ceram Int 44:5939-5944

14. Klockner W, Yadav RM, Yao J, Lei S, Aliyan A, Wu J, Martí AA, Vajtai R, Ajayan PM, Denardin JC, Serafini D, Melo F, Singh DP (2017) Acetonitrile mediated facile synthesis and self-assembly of silver vanadate nanowires into 3D spongy-like structure as a cathode material for lithium ion battery. J. Nanoparticle Res 19:288

15. Tracey AS, Willsky GR, Takeuchi ES (2007) Vanadium: chemistry, biochemistry, pharmacology and practical applications, 1st edn. CRC Press, London

16. Liu Y, Zhang Y, Hu Y, Qian $Y$ (2005) Hydrothermal synthesis of single-crystal $\beta-\mathrm{AgVO}_{3}$ nanowires and ribbon-like nanowires. Chem Lett 34:146-147

17. Zhang S, Li W, Li C, Chen J (2006) Synthesis, characterization, and electrochemical properties of $\mathrm{Ag}_{2} \mathrm{~V}_{4} \mathrm{O}_{11}$ and $\mathrm{AgVO}_{3}$ 1-D nano/ microstructures. J Phys Chem B 110:24855-24863

18. de Oliveira RC, Assis M, Teixeira MM, da Silva MDP, Li MS, Andres J, Gracia L, Longo E (2016) An experimental and computational study of $\beta$-AgVO3: optical properties and formation of Ag nanoparticles. J Phys Chem C 120:12254-12264

19. Hu H, Yu A, Kim E, Zhao B, Itkis ME, Bekyarova E, Haddon RC (2005) Influence of the zeta potential on the dispersability and purification of single-walled carbon nanotubes. J Phys Chem B 109:11520-11524

20. Gao L, Li Z, Liu J (2017) Facile synthesis of $\mathrm{Ag}_{3} \mathrm{VO}_{4} / \beta-A g \mathrm{OO}_{3}$ nanowires with efficient visible-light photocatalytic activity. RSC Adv. 7:27515-27521

21. Krimm S, Tobolsky AV (1951) Quantitative x-ray studies of order in amorphous and crystalline polymers: quantitative 
$\mathrm{x}$-ray determination of crystallinity in polyethylene. J Polym Sci 7:57-76

22. de Castro DT, Valente MLC, da Silva CHL, Watanabe E, Siqueira RL, Schiavon MA, Alves OL, dos Reis AC (2016) Evaluation of antibiofilm and mechanical properties of new nanocomposites based on acrylic resins and silver vanadate nanoparticles. Arch Oral Biol 67:46-53

23. Byrappa K, Adschiri T (2007) Hydrothermal technology for nantechnology. Prog Cryst Growth Charact 53:117-166

24. Song J-M, Lin Y-Z, Yao H-B, Fan F-J, Li X-G, Yu S-H (2009) Superlong $\beta-\mathrm{AgVO}_{3}$ nanoribbons: high-yield synthesis by a pyridineassisted solution approach, their stability, electrical and electrochemical properties. ACS Nano 3:653-660

25. Tian H, Wachs IE, Briand LE (2005) Comparison of UV and visible raman spectroscopy of bulk metal molybdate and metal vanadate catalysts. J Phys Chem B 109:23491-23499

26. Zhao W, Guo Y, Faiz Y, Yuan W-T, Sun C, Wang S-M, Deng Y-H, Zhuang Y, Li Y, Wang X-M, He H, Yang S-G (2015) Facile in-suit synthesis of $\mathrm{Ag} / \mathrm{AgVO}_{3}$ one-dimensional hybrid nanoribbons with enhanced performance of plasmonic visible-light photocatalysis. Appl Catal B 163:288-297

27. Zhou Q, Shao M, Que R, Cheng L, Zhuo S, Tong Y, Lee S-T (2011) Silver vanadate nanoribbons: a label-free bioindicator in the conversion between human serum transferrin and apotransferrin via surface-enhanced Raman scattering. Appl Phys Lett 98:193110

28. de Oliveira RC, Assis M, Teixeira MM, da Silva MDP, Li MS, Andres J, Gracia L, Longo E (2016) An experimental and computational study of $\beta-\mathrm{AgVO}_{3}$ : optical properties and formation of Ag nanoparticles. J Phys Chem C 120:12254-12264

29. Liang S, Zhou J, Pan A, Li Y, Chen T, Tian Z, Ding H (2012) Facile synthesis of $\beta-\mathrm{AgVO}_{3}$ nanorods as cathode for primary lithium batteries. Mater Lett 74:176-179

30. Wang C-B, Deo G, Wachs IE (1999) Interaction of polycrystalline silver with oxygen, water, carbon dioxide, ethylene, and methanol: in situ Raman and catalytic studies. J Phys Chem B 103:5645-5656

31. Bao Q, Bao S, Li CM, Qi X, Pan C, Zang J, Wang W, Tang DY (2007) Lithium insertion in channel-structured $\beta-\mathrm{AgVO}_{3}$ : in situ Raman study and computer simulation. Chem Mater 19:5965-5972

32. Souza Filho AG, Ferreira OP, Santos EJG, Mendes Filho J, Alves OL (2004) Raman spectra in vanadate nanotubes revisited. Nano Lett 4:2099-2104

33. Zhang WF, He YL, Zhang MS, Yin Z, Chen Q (2000) Raman scattering study on anatase $\mathrm{TiO}_{2}$ nanocrystals. J Phys D 33:912-916

34. Keramidas VG, White WB (1974) Raman scaterring study of the crystallization and phase transformations of $\mathrm{ZrO}_{2}$. J Am Ceram Soc 57:22-24

35. Bao Q, Bao S, Li CM, Qi X, Pan C, Zang J, Wang W, Tang DY (2007) Lithium insertion in channel-structured $\beta-\mathrm{AgVO}_{3}$ : in situ Raman study and computer simulation. Chem Mater 19:5965-5972

36. Grover V, Banerji A, Sengupta P, Tyagi AK (2008) Raman, XRD and microscopic investigations on $\mathrm{CeO}_{2}-\mathrm{Lu}_{2} \mathrm{O}_{3}$ and $\mathrm{CeO}_{2}-\mathrm{SC}_{2} \mathrm{O}_{3}$ systems: a sub-solidus phase evolution study. J Solid State Chem 181:1930-1935

37. Mandal BP, Grover V, Roy M, Tyagi AK (2007) X-ray diffraction and Raman spectrocopic investigation on the phase relations in $\mathrm{Yb}_{2} \mathrm{O}_{3}$ - and $\mathrm{Tm}_{2} \mathrm{O}_{3}$-substituted $\mathrm{CeO}_{2}$. J Am Ceram Soc 90:2961-2965

38. Nakajima A, Yoshihara A, Ishigame M (1994) Defect-induced Raman spectra in doped $\mathrm{CeO}_{2}$. Phys Rev B 50:13297-13307
39. Rodríguez-Clemente R, López-Macipe A, Gómez-Morales J, Torrent-Burgés J, Castaño VM (1998) Hydroxyapatite precipitation: a case of nucleation-aggregation-agglomeration-growth mechanism. J Eur Ceram Soc 18:1351-1356

40. Zhou L, Wang W, Zhang L, Xu H, Zhu W (2007) Single-crystalline $\mathrm{BiVO}_{4}$ microtubes with square cross-sections: microstructure, growth mechanism, and photocatalytic property. J Phys Chem C 111:13659-13664

41. Montanheiro TLA, Montagna LS, de Farias MA, Magalhães JA, Tada DB, Passador FR, Machado JPB, Lemes AP (2018) Cytotoxicity and physico-chemical evaluation of acetylated and pegylated cellulose nanocrystals. J Nanoparticle Res 20:206

42. Lee J, Kim M, Hong CK, Shim SE (2007) Measurement of the dispersion stability of pristine and surface-modified multiwalled carbon nanotubes in various nonpolar and polar solvents. Meas Sci Technol 18:3707-3712

43. Mirhosseini H, Tan CP, Hamid NSA, Yusof S (2008) Effect of Arabic gum, xanthan gum and orange oil contents on $\zeta$-potential, conductivity, stability, size index and $\mathrm{pH}$ of orange beverage emulsion. Colloids Surf A Physicochem Eng Asp 315:47-56

44. Pan G-T, Lai M-H, Juang R-C, Chung T-W, Yang TC-K (2011) Preparation of visible-light-driven silver vanadates by a microwaveassisted hydrothermal method for the photodegradation of volatile organic vapors. Ind Eng Chem Res 50:2807-2814

45. Huang C-M, Cheng K-W, Pan G-T, Chang W-S, Yang TC-K (2010) CTAB-assisted hydrothermal synthesis of silver vanadates and their photocatalytic characterization. Chem Eng Sci 65:148-152

46. Mittal KL (2012) Adhesion aspects of polymeric coatings. Springer, New York

47. Stumm W (1992) Chemistry of solid-water interface: processes at the mineral-water and particle-water interface in natural systems. Wiley, New York

48. Artal MC, Holtz RD, Kummrow F, Alves OL, Umbuzeiro GDA (2013) The role of silver and vanadium release in the toxicity of silver vanadate nanowires toward Daphnia similis. Environ Toxicol Chem 32:908-912

49. Geffers M, Groll J, Gbureck U (2015) Reinforcement strategies for load-bearing calcium phosphate biocements. Materials 8:2700

50. Sivakumar V, Suresh R, Giribabu K, Narayanan V (2015) $\mathrm{AgVO}_{3}$ nanorods: synthesis, characterization and visible light photocatalytic activity. Solid State Sci 39:34-39

51. Zhang S, Min L (2011) Hydrothermal synthesis and optical characterization of 1-D $\mathrm{AgVO}_{3}$ and $\mathrm{Ag}_{2} \mathrm{~V}_{4} \mathrm{O}_{11}$ nano/microstructures. Adv Sci Lett 4:3701-3705

52. Ju P, Fan H, Zhang B, Shang K, Liu T, Ai S, Zhang D (2013) Enhanced photocatalytic activity of $\beta$-AgVO3 nanowires loaded with Ag nanoparticles under visible light radiation. Sep Purif Technol 109:107-110

53. Lin $X$, Guo X, Shi W, Guo F, Zhai H, Yan Y, Wang Q (2015) $\mathrm{Ag}_{3} \mathrm{PO}_{4}$ quantum dots sensitized $\mathrm{AgVO}_{3}$ nanowires: a novel $\mathrm{Ag}_{3} \mathrm{PO}_{4} /$ $\mathrm{AgVO}_{3}$ nanojunction with enhanced visible-light photocatalytic activity. Catal Commun 66:67-72

Publisher's Note Springer Nature remains neutral with regard to jurisdictional claims in published maps and institutional affiliations. 